\title{
The Magpie Trial: a randomised trial comparing magnesium sulphate with placebo for pre-eclampsia. Outcome for children at 18 months
}

\author{
Magpie Trial Follow-Up Study Collaborative Group \\ Correspondence: Dr L Duley, Magpie Trial Office, Nuffield Department of Medicine, Level 5, John Radcliffe Hospital, Headington, \\ Oxford OX3 9DU, UK. Email lelia.duley@ndm.ox.ac.uk
}

Accepted 4 October 2006. Published OnlineEarly 12 December 2006.

Objective To assess the long-term effects of in utero exposure to magnesium sulphate for children whose mothers had pre-eclampsia.

Design Assessment at 18 months of age for children whose mothers were recruited to the Magpie Trial (recruitment 1998-2001 ISRCTN 86938761), which compared magnesium sulphate with placebo.

Setting Follow-up of children born at 125 centres in 19 countries across five continents.

Population A total of 6922 children were born to women randomised before delivery at follow-up centres. Of these, 2271 were not included for logistic reasons and 168 were excluded (101 at a centre where $<20 \%$ were contacted, 40 whose death or disability was due to a problem at conception or embryogenesis and 27 whose parent/s opted out). Therefore, 4483 children were included in follow-up, of whom 3283 (73\%) were contacted.
Methods Assessment by questionnaire, with interview and neurodevelopmental testing of selected children.

Main outcome measures Death or neurosensory disability at age of 18 months.

Results Of those allocated magnesium sulphate, 245/1635 (15.0\%) were dead or had neurosensory disability at 18 months compared with 233/1648 (14.1\%) allocated placebo (relative risk [RR] 1.06, 95\% CI 0.90-1.25), and of survivors, 19/1409 (1.3\%) had neurosensory disability at 18 months compared with $27 / 1442$ (1.9\%) (RR 0.72, 95\% CI 0.40-1.29). There were no substantial differences in causes of death or in the risk of individual impairments or disabilities.

Conclusions The lower risk of eclampsia following prophylaxis with magnesium sulphate was not associated with a clear difference in the risk of death or disability for children at 18 months.

Keywords Longterm follow-up, magnesium sulphate, pre-eclampsia, randomised trial.

Please cite this paper as: Magpie Trial Follow-Up Study Collaborative Group. The Magpie Trial: a randomised trial comparing magnesium sulphate with placebo for pre-eclampsia. Outcome for children at 18 months. BJOG 2007;114:289-299.

\section{Introduction}

Pre-eclampsia complicates $2-8 \%$ of pregnancies. ${ }^{1}$ Although outcome is often good, pre-eclampsia is a major cause of morbidity and mortality for women and children. ${ }^{2-4}$ Eclampsia, the occurrence of seizures superimposed on pre-eclampsia, is rare but associated with even higher morbidity and mortality, ${ }^{5}$ particularly in developing countries. ${ }^{3}$ Magnesium sulphate is the anticonvulsant of choice for women with

Re-use of this article is permitted in accordance with the Creative Commons Deed, Attribution 2.5, which does not permit commercial exploitation. eclampsia. ${ }^{6-8}$ The Magpie Trial showed that it is also effective for preventing the first eclamptic seizure, without substantive short-term harmful effects on either mother or baby. ${ }^{9,10}$

The long-term impact of in utero exposure to magnesium sulphate is unclear. Case-control studies have suggested that maternal treatment shortly before birth may lower the risk of cerebral palsy in surviving very-lowbirthweight infants. ${ }^{11-13}$ A recent randomised trial found some evidence to support this view. ${ }^{14}$ However, trials comparing magnesium sulphate with alternative agents for tocolysis of preterm labour show an increase in the risk of fetal, neonatal or infant death associated with magnesium 
sulphate, ${ }^{15}$ although these studies used a higher dose (at least double), and gave it for considerably longer, than that in the Magpie Trial.

We contacted women recruited to the Magpie Trial when their children were 18 months or older. The main objective was to determine whether magnesium sulphate for preeclampsia affects the child's chance of surviving without major neurosensory disability.

\section{Methods}

Between 1998 and 2001, 8804 women with pre-eclampsia during pregnancy or labour were recruited to the Magpie Trial at 175 hospitals in 33 countries. ${ }^{10}$ They were randomly allocated to receive either magnesium sulphate or placebo as an intravenous loading dose followed by 24 hours of maintenance therapy. Treatment details have been reported elsewhere. ${ }^{10,16}$

These 8804 women gave birth to 9153 children, 9024 of whom were included in our analysis of outcome at discharge from hospital. ${ }^{10}$ Of these, 2102 babies were never eligible for follow-up; 127 who were unlikely to have been alive at trial entry (fetal heart beat not heard at trial entry and macerated stillbirth within 24 hours) and 1975 born at 50 centres, predominantly in developing countries, where follow-up was not thought possible either because reliable contact details were not available at discharge from hospital or because there was no local coordinator for the study. Children who ultimately participated in this follow-up study, having been born to the cohort of women recruited before delivery at the 125 centres in 19 countries participating in follow-up, are shown in Figure 1. All recruited children were included in follow-up at 92 centres ( 2145 children) and at least $90 \%$ at 106 centres (3330). Everyone involved in tracing and assessment remained blind to the allocated treatment. The protocol for follow-up is available elsewhere. ${ }^{17}$ Outcome for women ${ }^{18}$ and narrative accounts of the collaborators ${ }^{19}$ are published separately.

\section{Ethics approval and consent}

All hospitals secured local research ethics committee approval before starting recruitment to the main trial. Women were informed that they might be contacted for follow-up prior to giving consent for recruitment. Therefore, some centres did not require that the follow-up study be resubmitted to an ethics committee. Others required a new submission or considered the follow-up protocol as an amendment to the original trial protocol.

\section{How children were assessed}

Children were screened using the Ages and Stage Questionnaires (ASQs). ${ }^{20}$ Thirty questions cover the five domains: communication, gross motor, fine motor, problem solving and personal-social. To pass, the child has to pass all five domains. An additional section addresses general parental concerns, and it is not scored. We added two questions about use of health service resources. ${ }^{17} \mathrm{Up}$ to 24 months, age is adjusted for gestation at birth. Each questionnaire is valid for 4 weeks either side of the target age. This was extended by an additional week for each year of the child's age.

For centres where the full ASQ was not thought feasible for cultural or language reasons, we shortened the questionnaires by selecting the questions considered most likely to predict severe developmental delay. Three questions were selected in each of the gross motor, communication and problem solving domains, together with five general questions. ${ }^{17}$ To pass, the child had to have at least one 'yes' in each domain.

Questionnaires were available in English and Spanish. They were sent by post, administered in clinic (usually a clinic provided for children within the study) or during a home visit, or completed over the telephone. If the family could not be contacted directly, information about whether the child was 'alive and well' was collected, whenever possible. The aim was to assess children when they were at least 18 months, but this varied depending upon what was feasible.

Children who passed the ASQ for their own age, or for an older age group, were considered screen negative. Children who failed the ASQ were considered screen positive. Also considered screen positive were children whose ASQ was incomplete and could not be scored and those who passed the ASQ for children in a younger age group. Screen-positive children, and a sample of screen-negative children, were invited for a clinical and neurodevelopmental assessment using the Bayley Scales of Infant Development (BSID-II) ${ }^{21}$ or the Griffiths Tests, ${ }^{22}$ or an alternative test if neither was available. If no test was possible, we relied on clinical history and examination, including information about nonneurosensory disability (see below) using the Health Status Questionnaire. ${ }^{23}$ The person doing this assessment was usually aware of whether or not the child had passed the ASQ.

In the UK, the Office for National Statistics provided the date and cause for all deaths. When surviving UK children were at least 18 months old, a questionnaire was also sent to their GP asking about neurosensory function and general health.

\section{Data review}

Data for each child who died, or was thought might have disability, were reviewed by an independent paediatrician. A second paediatrician reviewed a $10 \%$ random sample of these, plus any with uncertainty about the diagnosis. Outcome was determined by consensus. Data for a $20 \%$ sample of children considered screen negative were also reviewed, together with all those who had a short ASQ only.

\section{Outcome measures}

The primary outcome for the follow-up study was the composite measure of death or neurosensory disability at age of 


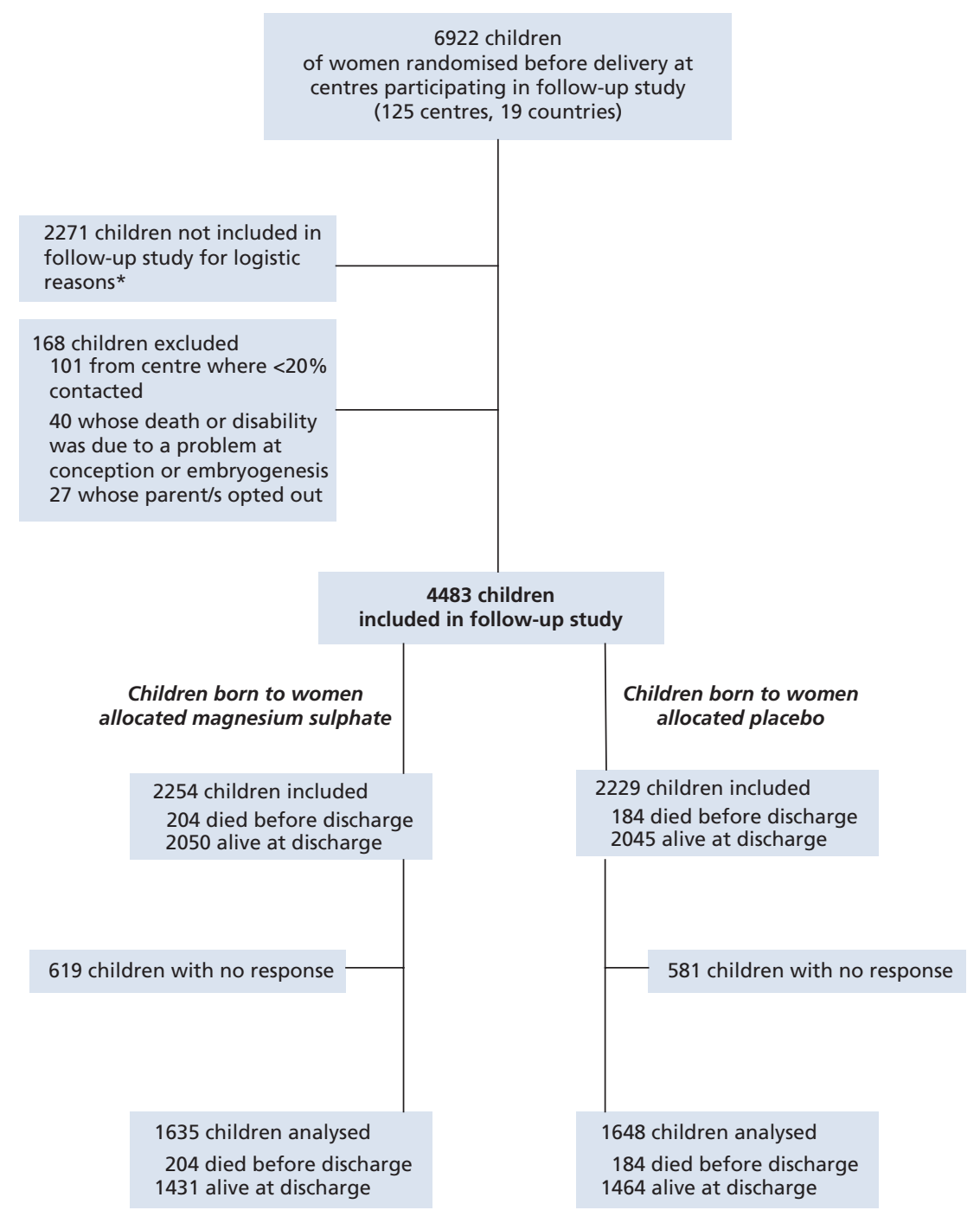

* At some centres, children were included in follow-up only if they were born within a pre-specified time frame, such as the past 1 or 2 years of recruitment (32 centres) or if they lived in a predefined geographic area (1)

Figure 1. Consort flow for children included in follow up.

18 months. ${ }^{17}$ Secondary outcomes for the children were death alone, each individual measure of neurosensory disability alone, delayed speech, other disability and contact with health services.

\section{Definitions of outcome measures for the children}

Death or neurosensory disability at 18 months of age (primary outcome)

The time point of at least 18 months (corrected for gestation at birth) provided the best balance between feasibility of follow up and certainty of diagnosis. Excluded were (a) cases where death or neurosensory disability was judged to have had its origin at conception or during embryogenesis, (b) deaths after 18 months and (c) disability clearly caused by some event occurring after 18 months. Four children were classified as fulfilling the criteria for inclusion in the composite primary outcome because, although only 12-17 months old when last seen, they were clearly disabled and would be dead or disabled at 18 months (magnesium sulphate, $n=3$; placebo, $n=1$ ).

Children were classified as having neurosensory disability if they were functionally blind (binocular visual acuity $<6 / 60$ ) or deaf (severe enough to need a hearing aid), had severe cerebral palsy (not walking or unlikely to walk unaided by 24 months ${ }^{14}$ ) or had a developmental quotient $(D Q)<-2$ SD. Children with a DQ $<-2$ SD were classified as having definite delay, as were children whose developmental progress was less than that would be expected of an average child half that age. 
When development had only been assessed clinically or using the Denver Developmental Screening Test-2 (DDST-II) ${ }^{24}$ or its derivative the Lejarraga and Krupitzky test, ${ }^{25}$ children were classed as being 'likely' to have developmental delay if progress in at least one domain was clearly less than that was to be expected of a child two-thirds that age. Of the 1288 children who had neurodevelopmental assessment, this was the Lejarraga and Krupitzky ${ }^{25}$ for 743 , BSID-II ${ }^{21}$ for 367 , DDST-II ${ }^{24}$ for 49 , Griffiths ${ }^{22}$ for 46 , Baroda (a derivative of the BSID-II) ${ }^{26}$ for 14 and other tests for 69.

\section{Other disability}

Children with non-neurosensory disability alone (such as needing continuous supplemental oxygen, breathing support, renal dialysis, frequent seizures despite treatment and tube or parenteral feeding) ${ }^{23}$ were classified as having 'other disability'. So too were children whose cerebral palsy was judged to be not severe.

\section{Isolated speech delay}

Children with a vocabulary of less than ten words at 24 corrected months but no other developmental problem ${ }^{23}$ were classified as having isolated speech delay, as were older children with equivalent degrees of speech delay.

\section{Power of the study}

We anticipated that 2680-3210 children whose mothers were randomised before delivery would be eligible. We estimated the composite primary outcome (death or neurosensory disability) might affect $20-25 \%$ of children in the placebo group. After adjustment for expected losses to follow up, it was anticipated that there would be data on death or disability for 2370-2810 children. This would give $70-80 \%$ power (alpha 0.05 ) to detect a relative difference between the groups of $20 \%$ in the primary outcome. ${ }^{17}$

\section{Statistical analyses}

Analyses were based on the groups to which the women and children had been allocated at trial entry. Centres able to contact $<20 \%$ of included families were excluded. Where appropriate, results are presented as relative risk (RR) with 95\% confidence intervals $(\mathrm{CI})$.

Sensitivity analyses for the composite primary outcome were pre-specified ${ }^{17}$ as: excluding children classified as having 'likely disability', including children whose death or neurosensory disability originated during conception or embryogenesis, excluding centres where $<90 \%$ of randomised children were selected for follow up or where selection was not based on a time frame and including centres where $80 \%$ or more of the children could not be contacted.

Planned subgroup analyses ${ }^{17}$ were based on the following: severity of the mother's pre-eclampsia at trial entry (severe, moderate, mild), gestation at birth ( $\leq 33$ completed weeks,
$>33$ completed weeks), perinatal mortality (PNM) in the country (high, medium or low) ${ }^{27}$ and whether the mother received maintenance therapy of trial treatment by the intramuscular or the intravenous route. In addition, a post hoc Poisson regression was conducted for the primary outcome adjusting for gestation at birth, whether the mother had an anticonvulsant before trial entry, PNM in country, route of maintenance therapy, sex of the baby, multiple pregnancy and whether admitted to a special care baby unit.

The analysis of children's death alone included all deaths and took account of the age at death, using log-rank survival analysis. Cause of death for the babies was classified using standard criteria. ${ }^{28,29}$

\section{Results}

Overall, 125 centres in 19 countries in Africa, Asia, the Americas, Australia and Europe participated in follow-up. The coordinating centre in Oxford traced children from the $67 \mathrm{UK}$ centres. Local collaborators traced all other children. Data collection closed on 31 December 2003. For 27 children, the parent/s or carers opted out of follow up. Of these, 16 were 'alive and well' when contacted. There is no information on the other 11 children. Also excluded from the analyses were 40 children who died $(n=26)$ or had disability due to a problem originating at conception or embryogenesis (14). Two of these surviving children also had cerebral palsy.

Included in the follow-up study were 4483 children whose mothers were randomised before birth (magnesium sulphate, $n=2254$; placebo, $n=2229)$ (Figure 1), of whom $388(9 \%)$ were stillborn or died before discharge from hospital and 4095 (91\%) were alive at discharge. The main substantive differences between children included in follow-up and those in the trial overall were that a higher proportion came from low or middle PNM countries (61\% in follow up versus $43 \%$ in the trial overall). Therefore, most of their mothers received the intravenous maintenance regimen for magnesium sulphate (63\% versus 52\%). ${ }^{10}$ Also, fewer children included in follow-up were born before 33 completed weeks (23\% versus $27 \%$ ).

\section{Completeness and review of data}

Data for 3283 children (73\%) were available for analysis (magnesium sulphate, $n=1635$; placebo, $n=1648$ ) (Figure 1). For 106 children in the UK, information was from the GP only. In the UK, $98 \%$ of children were contacted. Outside the UK, 11 centres contacted all included children and 36 contacted more than half of included children. Data were available for $57 \%$ of children in high PNM countries (994/1744), 75\% in middle PNM countries (1213/1609) and 95\% in low PNM countries (1076/1130) (Table 1). Outcome at discharge from hospital was similar for children included and for those contacted (Table 1). 
Table 1. Characteristics at trial entry, exposure to magnesium sulphate and outcome at discharge from hospital for children included in follow-up and those contacted

\begin{tabular}{|c|c|c|c|c|}
\hline & \multicolumn{2}{|c|}{ Children included in follow-up } & \multicolumn{2}{|c|}{ Children contacted } \\
\hline & MgSO4, $n=2254$ & Placebo, $n=2229$ & MgSO4, $n=1635$ & Placebo, $n=1648$ \\
\hline \multicolumn{5}{|l|}{ Mothers' characteristics at trial entry } \\
\hline Singleton pregnancy & $2094(93)$ & $2096(94)$ & $1522(93)$ & $1554(94)$ \\
\hline \multicolumn{5}{|l|}{ Pre-eclampsia } \\
\hline Severe & $526(23)$ & $553(25)$ & $395(24)$ & $421(26)$ \\
\hline Moderate & $1047(47)$ & $990(44)$ & $721(44)$ & $709(43)$ \\
\hline Mild & $691(30)$ & $686(31)$ & $519(32)$ & $518(31)$ \\
\hline Prior anticonvulsant & $160(7)$ & $167(7)$ & $110(7)$ & $110(7)$ \\
\hline$\leq 33$ completed weeks of gestation & $529(23)$ & $522(24)$ & $398(24)$ & $396(24)$ \\
\hline Intravenous maintenance regimen & $1429(63)$ & $1391(61)$ & $1142(70)$ & $1118(68)$ \\
\hline High PNM country & $864(38)$ & $880(40)$ & $479(29)$ & $515(32)$ \\
\hline Middle PNM country & $823(37)$ & $786(35)$ & $617(38)$ & $596(36)$ \\
\hline Low PNM country & $567(25)$ & $563(25)$ & $539(33)$ & $537(33)$ \\
\hline \multicolumn{5}{|l|}{ After trial entry } \\
\hline \multicolumn{5}{|l|}{ Exposure to $\mathrm{MgSO}_{4}$} \\
\hline None & $85(4)$ & $2216(99)$ & $70(4)$ & $1638(99)$ \\
\hline Median (IQR) (g) & $14(5-29)$ & 0 & $18(9-29)$ & 0 \\
\hline Time to delivery, median (IQR) (hours) & $12(4-42)$ & $11(4-39)$ & $12(4-46)$ & $11(4-46)$ \\
\hline \multicolumn{5}{|l|}{ Outcome at discharge from hospital } \\
\hline Born $\leq 33$ completed weeks & $435(19)$ & $418(19)$ & $331(20)$ & $326(20)$ \\
\hline Stillbirth or died before discharge & $204(9)$ & $184(8)$ & $204(12)$ & $184(11)$ \\
\hline In special care baby unit* & $804(38)$ & $773(37)$ & $576(38)$ & $556(36)$ \\
\hline \multicolumn{5}{|c|}{$\begin{array}{l}\text { IQR, interquartile range. } \\
\text { Data are } n(\%) \text { unless otherwise indicated. } \\
\text { *Liveborn babies only: selected children in } \mathrm{MgSO}_{4} \text { group, } n=2132 \text {, and in placebo group, } n=2108 \text {; contacted children in } \mathrm{MgSO}_{4} \mathrm{group} \\
n=1513 \text {, and in placebo group, } n=1527 \text {. }\end{array}$} \\
\hline
\end{tabular}

There was $88 \%$ agreement on the data review, with all discrepancies resolved by discussion. For 73 children, the neurodevelopmental test was overruled as having been incorrectly applied (magnesium sulphate, $n=34$ and placebo, $n=39$ ).

\section{ASQ performance}

Of the 2610 children for whom an ASQ was completed, 86\% (2233) had at least one long ASQ and 15\% (377) had the short ASQ only (Table 2). Overall, $636(24 \%)$ were considered screen positive, of whom 549 (86\%) had further assessment (Table 3). How well the full ASQ distinguished between children likely to have or not to have neurosensory disability is summarised in Table 4. No children passed the ASQ and were later found to have neurosensory disability among either the 377 screened with the short ASQ only or the 215 screened with the full ASQ when aged younger than 18 months. Data were reviewed for 436 children who passed the full ASQ; 122 were reviewed because additional information in the general questions or elsewhere suggested that they might have disability and 314 randomly selected from the remainder, three of whom had neurosensory disability.

\section{Outcome for the children}

Of the children whose mothers were allocated magnesium sulphate, $245 / 1635(15.0 \%)$ had the primary outcome of death or noncongenital neurosensory disability compared with 233/1648 (14.1\%) allocated placebo (RR 1.06, 95\% CI 0.90-1.25) (Table 5). This result was consistent across the pre-specified subgroups (Figure 2), and it was not substantially altered by any pre-specified sensitivity analysis (data not shown) or by adjusting for major prognostic factors (RR 1.07, 95\% CI 0.92-1.24) or after excluding children seen only when younger than 18 months (RR 1.10, 95\% CI 0.93-1.29).

There was no significant difference between the groups in the risk of neurosensory disability at 18 months (19/1409 versus 27/1442; RR 0.72, 95\% CI 0.40-1.29). Fifteen children were identified as having cerebral palsy ( 5 versus 10 ); this was severe for 12 (3 versus 9). Two were from a country with high PNM, seven with middle PNM and six with low PNM.

Of the 2895 children alive at discharge and traced, 44 (1.7\%) died after discharge; there were no substantial differences in causes of death (Table 6). In total, 226/1635 (13.8\%) of children in the magnesium group were stillborn or died 
Table 2. For children alive at discharge from hospital and traced: information from tracing and screening

\begin{tabular}{|c|c|c|}
\hline & $\begin{array}{l}\mathrm{MgSO}_{4} \\
n=1431\end{array}$ & $\begin{array}{l}\text { Placebo, } \\
n=1464\end{array}$ \\
\hline ASQs completed & $1283(90)$ & $1327(91)$ \\
\hline At least one full ASQ & 1101 & 1132 \\
\hline Short ASQ only & 182 & 195 \\
\hline No ASQ & $148(10)$ & $137(9)$ \\
\hline $\begin{array}{l}\text { Information from GP } \\
\text { questionnaire (UK) }\end{array}$ & 59 & 47 \\
\hline 'Alive and well' only information & 63 & 63 \\
\hline Child dead & 24 & 25 \\
\hline $\begin{array}{l}\text { Paediatric assessment } \\
\text { but no ASQ }\end{array}$ & 2 & 2 \\
\hline \multicolumn{3}{|l|}{ ASQ scoring } \\
\hline Complete & $1186(83)$ & $1186(81)$ \\
\hline Ratio score for full ASQ & $87(6)$ & $128(9)$ \\
\hline Incomplete and unable to score & $10(1)$ & $13(1)$ \\
\hline \multicolumn{3}{|l|}{ When ASQ completed } \\
\hline Within correct time frame* & $1070(75)$ & $1049(72)$ \\
\hline Outside correct time frame & $213(15)$ & 278 (19) \\
\hline ASQ for an older age group & 131 & 162 \\
\hline ASQ for a younger age group & 82 & 116 \\
\hline Failed ASQ & $240(17)$ & $226(16)$ \\
\hline $\begin{array}{l}\text { ASQ for correct age or an } \\
\text { older age group }\end{array}$ & 229 & 209 \\
\hline ASQ for a younger child & 11 & 17 \\
\hline
\end{tabular}

compared with 206/1648 (12.5\%) allocated placebo (RR 1.11, 95\% CI 0.93-1.32) (Table 6).

Of the children for whom we had either a completed ASQ or information from their GP, more than half were reported to have attended a clinic since discharge from hospital after delivery (759/1342 versus 729/1374) and almost one-quarter had been admitted to hospital (292/1342 versus 301/1374). There were no substantial differences in these outcomes between the treatment groups. The most common reason for hospital admission was respiratory problems (106 versus 109).

\section{Discussion}

Our earlier report showed that magnesium sulphate is effective for prevention of eclampsia. ${ }^{10}$ Results presented here provide reassurance about safety for the children in the longer term and are generalisable to both developed and developing countries. Magnesium sulphate for pre-eclampsia was not associated with any substantive reduction in survival without neurosensory disability for the children exposed while in utero.

When the Magpie Trial was designed, follow-up was planned in the UK only. Once it became clear that more than
Table 3. For children alive at discharge from hospital: further assessment after tracing and screening

\begin{tabular}{|c|c|c|}
\hline & $\begin{array}{l}\text { MgSO4, } \\
n=1431\end{array}$ & $\begin{array}{l}\text { Placebo, } \\
n=1464\end{array}$ \\
\hline $\begin{array}{l}\text { Outcome determined without } \\
\text { further assessment }\end{array}$ & $25(2)$ & $26(2)$ \\
\hline Known severe neurosensory disability & 1 & 1 \\
\hline Child died after discharge & 24 & 25 \\
\hline Screen-positive children* & $311(22)$ & $325(22)$ \\
\hline $\begin{array}{l}\text { Clinical assessment }+ \\
\text { neurodevelopmental test }\end{array}$ & 217 & 215 \\
\hline Clinical assessment alone & 51 & 66 \\
\hline ASQ only, no further assessment & 43 & 44 \\
\hline $\begin{array}{l}\text { Screening to assessment (days), } \\
\text { median (IQR) }\end{array}$ & $5(0-55)$ & $3(0-52)$ \\
\hline Screen-negative children** & $972(69)$ & $1002(68)$ \\
\hline $\begin{array}{l}\text { Clinical assessment }+ \\
\text { neurodevelopmental test }\end{array}$ & 413 & 440 \\
\hline Clinical assessment alone & 245 & 241 \\
\hline ASQ only, no further assessment & 314 & 321 \\
\hline $\begin{array}{l}\text { Screening to assessment (days): } \\
\text { median (IQR) }\end{array}$ & $0(0-6)$ & $0(0-4)$ \\
\hline $\begin{array}{l}\text { No ASQ but had } \\
\text { neurodevelopmental test }\end{array}$ & 2 & 1 \\
\hline \multicolumn{3}{|l|}{$\begin{array}{l}\text { Child's age at assessment or when } \\
\text { known to be 'alive and well' }\end{array}$} \\
\hline$<12$ months & 20 & 31 \\
\hline 12-17 months & 195 & 135 \\
\hline $18-23$ months & 219 & 259 \\
\hline$\geq 24$ months & 914 & 967 \\
\hline Data from GP only & 59 & 47 \\
\hline Data reviewed by paediatrician ${ }^{\dagger}$ & $685(48)$ & $739(50)$ \\
\hline Considered screen-positive & 311 & 326 \\
\hline Considered screen-negative & 355 & 397 \\
\hline Died after discharge & 24 & 25 \\
\hline No ASQ & 19 & 16 \\
\hline
\end{tabular}

$\mathrm{IQR}$, interquartile range.

Data are $n(\%)$ unless otherwise indicated.

*Children who failed the ASQ regardless of whether or not within the correct time frame, or who passed it but the ASQ was for a younger age group or whose ASQ could not be scored.

${ }^{*}$ Children who passed the ASQ for their correct age or for an older age group.

${ }^{\dagger}$ Data also reviewed for the 388 children who died before discharge.

$80 \%$ of recruitment was from developing countries, it seemed imperative to at least try to contact a sample of these women and children. Although 50 centres were unable to participate in follow-up, this could not have introduced bias into the assessment of outcome, as randomisation had been stratified by centre. For the 125 centres that did participate in followup, $74 \%$ included follow up of all children recruited and $85 \%$ included at least $90 \%$ of children. The decision about who was included in follow-up was made at the start of the study, blind 
Table 4. For children with a full ASQ: screening result and whether the child had neurosensory disability

\begin{tabular}{|c|c|c|c|}
\hline \multirow[t]{2}{*}{ ASQ outcome } & \multicolumn{3}{|c|}{ Neurosensory disability } \\
\hline & Yes* & No & Total \\
\hline Failed** & 42 & 538 & 580 \\
\hline Passed & $3 * * *$ & 433 & 436 \\
\hline Total & 45 & 971 & 1116 \\
\hline \multicolumn{4}{|c|}{$\begin{array}{l}\text { *Includes likely neurosensory disability. } \\
\text { **Includes } 129 \text { who passed the ASQ for a younger age group, } 26 \\
\text { who failed the ASQ for a younger age group and } 20 \text { whose ASQ } \\
\text { could not be scored. Excluding those with an ASQ for a younger age } \\
\text { group, the negative predictive value is } 433 / 436=99.3 \% \text {. } \\
* * * \text { All were } \geq 18 \text { months when screened; two passed scored section } \\
\text { of the ASQ, but there was concern about hearing or speech in } \\
\text { general section. }\end{array}$} \\
\hline
\end{tabular}

to treatment allocation. The primary reason why some centres only tried to contact a proportion of children was that many of those born early in the trial would have changed address, possibly several times, and so would be impossible to trace. Hence, in these centres, children were only included in follow up if they were born after a pre-specified date. At one centre, an additional factor was that it was unsafe to visit certain geographic areas, so those with a discharge address within these pre-specified areas were not included. It is implausible that these factors could have been related to outcome, and as they are likely to be equally distributed between the treatment groups because of the randomisation, it is unlikely that they introduced any bias.

Having provided reassurance that there was no potential bias between the groups in the way children were selected for inclusion in follow-up, our pragmatic philosophy was that any information about outcome was better than none. This approach enabled us to trace families and assess children in situations where follow-up had previously been thought impossible. We are not aware of other perinatal trials that have conducted follow-up in a comparable range of countries and settings. Restricting the study to centres able to guarantee that a high proportion of children could be traced would have excluded most low-income countries. Overall, $73 \%$ of included children were contacted, which is a remarkable achievement. In many countries, there was a strong impression that women valued this continued interest in the welfare of their child. The chief exception was some rural communities, where strangers visiting a remote village might be regarded with suspicion.

A key challenge was to identify an appropriate and simple tool for screening large numbers of young children over a wide age range and in a variety of settings and countries. The ASQ ${ }^{20}$
Table 5. For all selected children: death or neurosensory disability

\begin{tabular}{|c|c|c|}
\hline & $\begin{array}{l}\text { MgSO4, } \\
n=1635\end{array}$ & $\begin{array}{l}\text { Placebo, } \\
n=1648\end{array}$ \\
\hline $\begin{array}{l}\text { Death after randomisation and } \\
\leq 18 \text { months }\end{array}$ & $226(13.8)$ & $206(12.5)$ \\
\hline Stillbirth or died before discharge & 204 & 184 \\
\hline Died after discharge & 22 & 22 \\
\hline Neurosensory disability* & $13(0.8)$ & $19(1.2)$ \\
\hline Blind & 3 & 3 \\
\hline Deaf & 2 & 1 \\
\hline Severe cerebral palsy & 3 & 9 \\
\hline Developmental delay & 11 & 15 \\
\hline Likely neurosensory disability & $6(0.4)$ & $8(0.5)$ \\
\hline Blind & - & - \\
\hline Deaf & 1 & - \\
\hline Severe cerebral palsy & - & - \\
\hline Developmental delay & 5 & 8 \\
\hline \multicolumn{3}{|c|}{ Death or neurosensory disability at 18 months } \\
\hline For all contacted children & $245(15.0)$ & $233(14.1)$ \\
\hline $\begin{array}{l}\text { For children followed until } \\
\text { either they developed } \\
\text { the primary outcome or } \\
\text { at least } 18 \text { months old** }\end{array}$ & $245(17.2)$ & $233(15.7)$ \\
\hline Other significant disability & $3(0.2)$ & $5(0.3)$ \\
\hline $\begin{array}{l}\text { Other cerebral palsy not } \\
\text { included above }\end{array}$ & 2 & 1 \\
\hline Other disability & - & $3 * * *$ \\
\hline Isolated speech delay & $23(1.4)$ & $29(1.8)$ \\
\hline Simple, probably transient & 22 & 27 \\
\hline Features suggestive of autism & 1 & 2 \\
\hline \multicolumn{3}{|c|}{$\begin{array}{l}\text { Data are } n(\%) \text {. } \\
\text { *Some children had more than one disability. One child with known } \\
\text { neurosensory disability did not have an ASQ. } \\
* * \mathrm{MgSO}_{4}, n=1421 \text {; placebo, } n=1480 \text {. } \\
\star * * \text { One child had each of the following: chronic oxygen dependency } \\
\text { at } 18 \text { months following viral chest infection at } 3 \text { months, apraxia, } \\
\text { Erbs palsy. }\end{array}$} \\
\hline
\end{tabular}

seemed to meet these criteria. Although it is user friendly, with pictures and clear text, each questionnaire is three pages. As this was initially thought to be rather long for some communities, especially those who were non-English speaking and predominantly rural, we shortened it to one page. In practice, many centres found administering the full ASQ less problematic than anticipated. Uptake of the short ASQ was therefore lower than expected.

The use of a variety of tools for neurodevelopmental assessment and that it was not possible for all children to have a full assessment were limitations of this study. Also, this follow-up has less power than the original trial as it was not feasible to include all children randomised, those included tended to be at lower risk of adverse outcome and it was harder to contact families in high PNM countries. These losses to follow-up do 


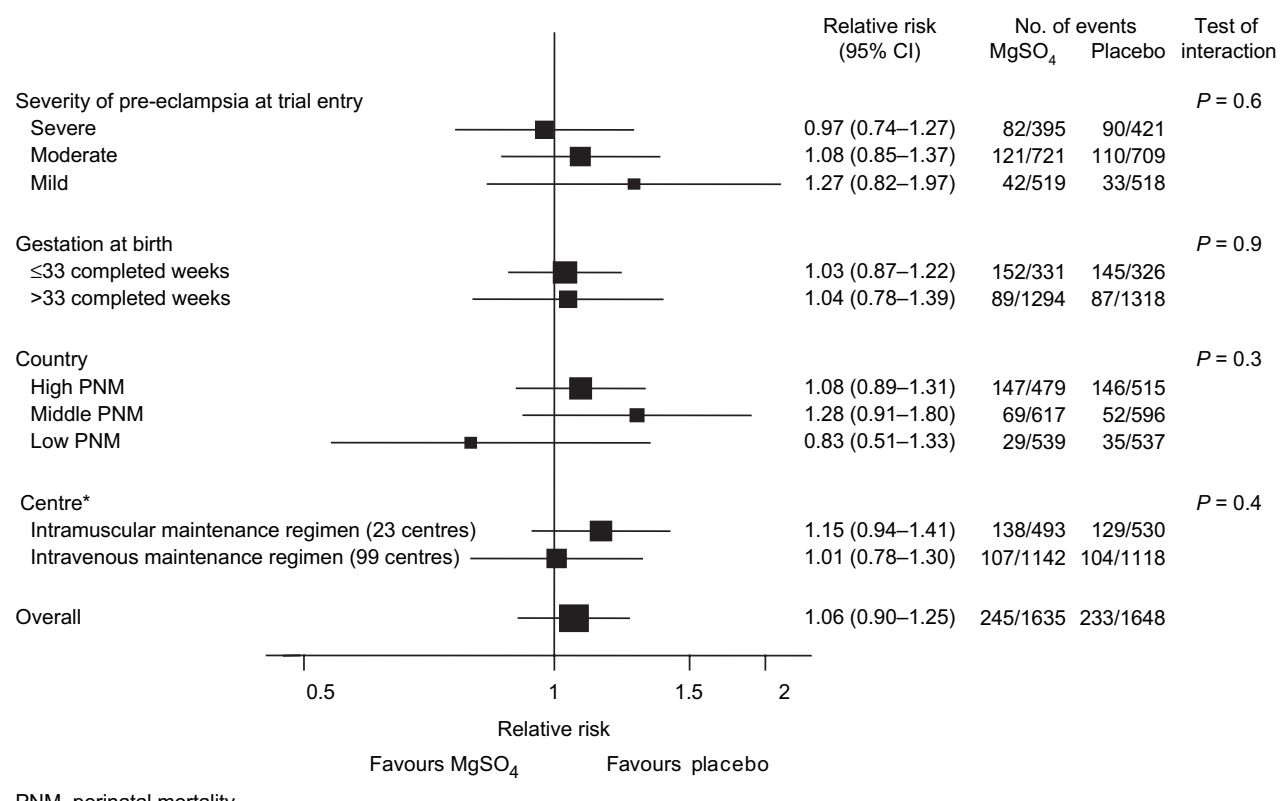

PNM, perinatal mortality.

* Excludes three centres: at two, no women were recruited before delivery; hence no children born to women randomised before birth; at another, all data excluded, as less than $20 \%$ of included children contacted.

Figure 2. Effects of treatment on death or neurosensory disability at the age of 18 months: subgroup analyses.

not appear to have had a substantive impact, however, as results are relatively consistent across countries with differing completeness of follow-up. In a blinded trial such as ours, it is unlikely that not being able to trace $27 \%$ of children after discharge would introduce appreciable bias in the conclu-

Table 6. For all children selected and traced: death and cause of death

\begin{tabular}{|c|c|c|}
\hline & $\begin{array}{l}\mathrm{MgSO}_{4} \\
n=1635\end{array}$ & $\begin{array}{l}\text { Placebo, } \\
n=1648\end{array}$ \\
\hline $\begin{array}{l}\text { Included in primary outcome } \\
\text { (died } \leq 18 \text { months) }\end{array}$ & $226(13.8)$ & $206(12.5)$ \\
\hline Stillbirth & 122 & 121 \\
\hline \multicolumn{3}{|l|}{ Liveborn } \\
\hline Died before discharge & 82 & 63 \\
\hline Died after discharge & 22 & 22 \\
\hline \multicolumn{3}{|l|}{ Not included in primary outcome } \\
\hline Died $>18$ months & 2 & 3 \\
\hline Total deaths & $228(13.9)$ & $209(12.7)$ \\
\hline \multicolumn{3}{|l|}{ Cause of death } \\
\hline Infection before/during birth & 2 & 1 \\
\hline Antepartum stillbirth* & 122 & 120 \\
\hline Preterm birth & 56 & 48 \\
\hline Intrapartum asphyxia/trauma & 20 & 13 \\
\hline Infection after birth & 15 & 14 \\
\hline External agent after birth & 1 & 2 \\
\hline Sudden infant death & 1 & 1 \\
\hline Unclassifiable & 11 & 10 \\
\hline
\end{tabular}

Data are $n(\%)$

*Does not include infection acquired before or during birth. sions, as the reasons for failure to contact them will have been equally true of children in both arms of the study. As those who were followed-up had been randomly exposed to magnesium sulphate, these data still allow an unbiased assessment of the treatment effect of antenatal magnesium sulphate on longer term outcomes. Moreover, the total numbers eventually followed, 2895 survivors from 3283 enrolled, are large relative to other antenatal trials and still allow power to detect uncommon adverse outcomes. By comparison, the Cochrane review of antenatal steroid therapy, ${ }^{30}$ the most obvious example of an antenatal intervention that has improved outcome for preterm infants, comprises data on only 3517 fetuses exposed, of whom 3184 survived and on whom long-term outcome data are reported for just 778 children.

Magnesium sulphate given as neuroprotection to women at risk of preterm birth before 30 weeks of gestation has been evaluated in one previous trial; ${ }^{14}$ there was a tendency to a lower risk of death or cerebral palsy at 2 years if the mothers were allocated magnesium sulphate rather than placebo (RR $0.83,95 \%$ CI $0.66-1.03)$. Nearly $8 \%$ of surviving babies in that study had cerebral palsy; only 17 surviving children were identified as having cerebral palsy in the present study, and in two of these, the problem was thought to have arisen during conception or embryogenesis. However, 10 of the other 15 children were among those whose mothers were allocated placebo (Table 5). The numbers involved are small, and this imbalance could have arisen by chance, but the trend is in the same direction as in the earlier trial. ${ }^{14}$ In our study, only one baby with cerebral palsy and $2.3 \%$ of all the babies were born before 30 weeks of gestation. 


\section{Conclusions}

Magnesium sulphate for women with pre-eclampsia more than halves the risk of eclampsia (RR 0.42, 95\% CI 0.29$0.60)$ and probably reduces the risk of maternal death before discharge from hospital (RR 0.55, 95\% CI $0.26-$ 1.14) compared with placebo. No substantive harmful effects were apparent in the short term, for either mother or baby. Exposure to magnesium sulphate while in utero was not associated with a clear difference in the risk of death or disability for children at 18 months. These data provide reasonable reassurance about the long-term safety of magnesium sulphate for the children, at the dosage used in our study.

\section{Acknowledgements}

This report is dedicated to the women and children, and their families, who participated in the follow-up study. The work was funded by the UK Medical Research Council, UK Department for International Development and the UNDP/UNFPA/WHO/World Bank Special Programme of Research, Development and Research Training in Human Reproduction. Each funding body had one observer on the trial steering committee. The funders had no other role in the study design, collection, analysis and interpretation of data, writing the final report or the decision to publish. $\mathrm{L}$ Duley had full access to all the data in the study and takes responsibility for the integrity of the data and the accuracy of the data analysis.

\section{Magpie Trial Follow-Up Study Collaborative Group}

\section{Central coordination and coordinating team for UK}

Lelia Duley (clinical coordinator), Barbara Farrell (trial manager), Nina Armstrong (follow-up study coordinator), Patsy Spark (trial programmer), Barbara Roberts (trial secretary), Rebecca Smyth (research midwife), Mary Tivnan (data manager), Anna Laws (research assistant), Noelene Corfield (data assistant), Annette Salter (data assistant) and Lisa Thorn (data assistant).

\section{Statistical support}

Douglas Altman and Ly-Mee Yu of Centre for Statistics in Medicine and Patsy Spark of Central coordinating team.

\section{Coordinating team for Argentina}

Edgardo Abalos (clinical coordinator), Berenise Carroli (coordinator), Lucrecia Dellepiane (field worker), Marina Duarte (paediatrician), Hebe Fernandez (field worker) and Daniel Giordano (programmer).

\section{Management group}

Douglas Altman, Nina Armstrong, Mike Clarke, Lelia Duley, Barbara Farrell (chair), Alastair Gray, Edmund Hey, James Neilson, Judit Simon, Patsy Spark, Rebecca Smyth and Ly-Mee Yu.

\section{Paediatric review}

Lex Doyle and Edmund Hey.

\section{Assessment advisors}

Tom Kelly (Newcastle, UK) and Jane Squires (Oregon, USA).

\section{Steering committee}

Douglas Altman, Rory Collins, Lelia Duley (observer), Barbara Farrell (observer), Anna Karaoglou (observer), Richard Lilford, Jack Moodley, James Neilson (observer), Stephen Robson, Ian Roberts, Peter Rubin (chair), James Thornton, Sara Twaddle, José Villar (observer), Isabel Walker and Christopher Watkins (observer).

\section{Writing committee}

Edgardo Abalos, Douglas Altman, Nina Armstrong, Lex Doyle, Lelia Duley (chair), Barbara Farrell, Edmund Hey, Jack Moodley, James Neilson, Patsy Spark, Rebecca Smyth and Ly-Mee Yu.

\section{Collaborators by country}

\section{Albania}

Maternity Hospital No. 2: A Bimbashi, E Demalia, O Gliozheni and A Shpata.

\section{Argentina}

Hospital Carlos A Durand: A Karolinski, M Lamas, M Pesaresi and V Wainer; Hospital Del Centenario: W Barbato; Hospital Eva Perón: M Paciocco; Hospital Interzonal Dr José Penna: M Bertin, E Boiza, J Castaldi and Y Partida; Hospital J B Iturraspe and Hospital Jose Maria Cullen: C Arias, M Farri and G Kerz; Hospital Juan R Vidal: J Aguirre, M de Sagastizábal, R Falcone and E Morales; Hospital Maternidad Martin: G Carroli; Hospital Nacional Prof. Alejandro Posadas: S Krupitzky, S López, M Palermo and D Montes Varela; Hospital Provincial Santa Fé: H Delprato; Hospital Regional 'Dr Ramón Carrillo': H Camusso and M Curioni; Hospital Roque Saénz Peña: E Ludmer; Luis Carlos Lagomaggiore: R Brandi, R Martin, W Mesas and R Taralli; Maternidad Provincial Salta (Nuevo del Milagro): M Lezaola and M Morosini; Materno Infantil 'Ramón Sardá': E Andina, L Bernal, M Estiú and E Ulens; Materno Provincial Córdoba: B Ortiz de Speranza and A Peyrano; Zonal de Agudos 'Héroes de Malvinas': M Damiano and C Saumench.

\section{Australia}

Royal Brisbane \& Women's Hospital Perinatal Research Centre: J Horn, M Pritchard, V Smith-Orr and M Wilson; The 
Townsville Hospital: A Lawrence and D Watson; Women's and Children's Hospital: C Crowther and J Paynter.

\section{Bangladesh}

Bangabandhu Sheikh Mujib Medical University: Ashrafunnessa, M Mannan, M Shahidullah and L Shamsuddin.

\section{Brazil}

Hospital das Clinicas Da UFPE: C Barros Santos, S Freire and E Melo.

\section{Colombia}

Fundaciòn Clínica Valle del Lili: E Cobo and M Jaramillo; Universidad Nacional de Colombia, Hospital Materno Infantil de Bogotá: C Cardozo, N Fandiño, H Gaitán and L Montaño; Hospital Universitario de San Ignacio: J Lozano and M Rojas.

\section{Cuba}

Docente Gineco-Obstétrico 'Eusebio Hernández': A Breto Garcíá, A Fuentes Ramirez, R García Mírás and S Sampera; Hospital Gineco-Obstétrico 'América Arias': U Farnot, E Gómez, G Rojas and R Valdés.

\section{Egypt}

Assiut University Hospital: H Abd El-Kreem, T Al-Hussaini and E Hammad.

\section{Ghana}

Komfo Anokye Teaching Hospital: K Danso, E Kwapong and F Ofosu-Barko.

\section{India}

Christian Medical College Hospital: M Padmini Jasper, A Peedicayil and A Regi; J N Medical College AMU: R Sharma; King Edward VII Memorial Hospital: A Chauhan, V Raut and R Udani; Maulana Azad Medical College and Loknayak Hospital: S Batra, A Muthal-Rathore, S Ramji and V Zutshi; SAT Hospital, Medical College Trivandrum: S Balakrishnan, E Eapen and G Koshy; Shree Maharani Shantadevi Hospital: B Ambardar, P Vadakkepat and D Vaidya.

\section{Malawi}

Queen Elizabeth Central Hospital: V Lema, Y Rijken and E Tadesse.

\section{Nigeria}

Centre for Research in Reproductive Health (coordination of hospitals in Sagamu region): O Dada and A Sofekun; Nigerian Security Printing and Minting Staff Hospital: C Ohiaeri; Olabisi Onabanjo University Teaching Hospital: $\mathrm{T}$ Runsewe-Abiodun; University College Hospital: I Adewole, A Adeyemo, B Brown and R Oladokun; University of Port
Harcourt: O Adewale, $\mathrm{N}$ Inimgba, $\mathrm{C}$ John and $\mathrm{R}$ Ogu; Usmanu Danfodiyo University Teaching Hospital: B Ekele, A Isah and B Onankpa.

Pakistan

Jinnah Post Graduate Medical Centre: R Jamelle and D Junejo; Lady Reading Hospital: N Ruby Faiz, F Gul and A Sherin; Maternal and Child Health Centre: K Bangash, G Mahmud, K Masud and N Tasneem.

Sierra Leone

Princess Christian Maternity Hospital: S Gassama and A Soyei.

Singapore

KK Women's and Children's Hospital: $\mathrm{P}$ Agarwal and V Rajadurai.

South Africa

Chris Hani Baragwanath Hospital: N Pirani; University of Pretoria (Kalafong Hospital and Pretoria Academic Hospital): S Delport, P Macdonald, R Mokhondo, R Pattinson and M Zondo; King Edward VIII Hospital: M Adhikari, N Mnguni and J Moodley; Tygerberg Hospital: M Carstens, G Kirsten, W Steyn and J van Zyl.

USA

OHSU Hospital: A Helwig, S-L Jacobson and R Panosche.

Zimbabwe

Harare Hospital: E Hammond and L Masanganise.

\section{References}

1 World Health Organization International Collaborative Study of Hypertensive Disorders of Pregnancy. Geographic variation in the incidence of hypertension in pregnancy. Am J Obstet Gynecol 1988;158:80-3.

2 The National Institute for Clinical Excellence, The Scottish Executive Health Department, The Department of Health Social Services and Public Safety Northern Ireland. Why Mothers Die 1997-1999: The Fifth Report of the Confidential Enquiries into Maternal Deaths in the United Kingdom. London: RCOG Press, 2001.

3 Duley L. Maternal mortality associated with hypertensive disorders of pregnancy in Africa, Asia, Latin America and the Caribbean. Br J Obstet Gynaecol 1992;99:547-53.

4 Department of Health. Confidential Enquiry into Stillbirths and Deaths in Infancy. London: Department of Health, 1996.

5 Douglas KA, Redman CW. Eclampsia in the United Kingdom. BMJ 1994;309:1395-400

6 Duley L, Gulmezoglu AM. Magnesium sulphate versus lytic cocktail for eclampsia. Cochrane Database Syst Rev 2000;CD002960 [DOI: 10.1002/14651858.CD002960].

7 Duley L, Henderson-Smart D. Magnesium sulphate versus phenytoin for eclampsia. Cochrane Database Syst Rev 2003;CD000128 [DOI: 10.1002/14651858.CD000128].

8 Duley L, Henderson-Smart D. Magnesium sulphate versus diazepam for eclampsia. Cochrane Database Syst Rev 2003;CD000127 [DOI: 10.1002/14651858.CD000127]. 
9 Duley L, Gülmezoglu AM, Henderson-Smart DJ. Magnesium sulphate and other anticonvulsants for women with pre-eclampsia. Cochrane Database Syst Rev 2003;CD000025 [DOI: 10.1002/14651858.CD000025].

10 Magpie Trial Collaborative Group. Do women with pre-eclampsia, and their babies, benefit from magnesium sulphate? The Magpie Trial: a randomised placebo-controlled trial. Lancet 2002;359:1877-90.

11 Nelson KB. Magnesium sulfate and risk of cerebral palsy in very lowbirth-weight infants. JAMA 1996;276:1843-4.

12 Nelson KB, Grether JK. Can magnesium sulfate reduce the risk of cerebral palsy in very low birthweight infants? Pediatrics 1995;95:263-9.

13 Schendel DE, Berg CJ, Yeargin-Allsopp M, Boyle CA, Decoufle P. Prenatal magnesium sulfate exposure and the risk for cerebral palsy or mental retardation among very low-birth-weight children aged 3 to 5 years. JAMA 1996;276:1805-10.

14 Crowther C, Hiller J, Doyle L, Haslam R; for the Australasian Collaborative Trial of Magnesium Sulphate (ACTOMgSO4) Collaborative Group. Effect of magnesium sulfate given for neuroprotection before preterm birth. JAMA 2003;290:2669-76.

15 Crowther CA, Hiller JE, Doyle LW. Magnesium sulphate for preventing preterm birth in threatened preterm labour. Cochrane Database Syst Rev 2002;CD001060 [DOI: 10.1002/14651858.CD001060].

16 Duley L, Carroli G, Farrell B, Moodley J, Neilson J; on behalf of the Magpie Trial Collaborative Group. The Magpie Trial. Lancet 2002;360:1331-2.

17 Magpie Trial Follow Up Study Management Group. The Magpie Trial Follow Up Study: outcome after discharge from hospital for women and children recruited to a trial comparing magnesium sulphate with placebo for pre-eclampsia [ISRCTN86938761]. BMC Pregnancy Childbirth. 2004;4:5.

18 Magpie Trial Follow Up Study Collaborative Group. The Magpie Trial: a randomised trial comparing magnesium sulphate with placebo for pre-eclampsia. Outcome for women at 2 years. BJOG DOI: 10.1111/ j.1471-0528.2006.01166.x.
19 Farrell B, Duley L. Doing the undoable: Magpie Trial long-term follow up. Lancet (in press).

20 Squires J, Potter L, Bricker D. The ASQ User's Guide for the Ages and Stages Questionnaires: A Parent-Completed, Child Monitoring System, 2nd edn. Baltimore, MD: Paul Brookes Publishing Co, 1999.

21 Bayley N. Manual for the Bayley Scales of Infant Development, 2nd edn. New York, NY: Psychological Corporation, 1993.

22 Griffiths R. The Abilities of Babies: A Study in Mental Measurement. Revised reprint. Association for Research in Infant \& Child Development, Amersham, UK, 1986.

23 Jones HP, Guildea ZES, Stewart JH, Cartlidge PHT. The Health Status Questionnaire: achieving concordance with published disability criteria. Arch Dis Child 2002;86:15-20.

24 Frankenburg W, Dodds J, Archer P, Shapiro H, Bresnick B. The Denver II: a major revision and restandardization of the Denver Developmental Screening Test. Pediatrics 1992;89:91-7.

25 Lejarraga H, Krupitzky S, y colaboradores. Guias para la evaluation del desarrollo en el nino menor de seis anos. Argentina: Nestle, 1996.

26 Phatak AT, Khurana B. Baroda development screening test for infants. Indian Pediatr 1990;28:31-7.

27 WHO. Perinatal Mortality: A Listing of Available Information, 7th edn. WHO/FRH/MSM/96. Geneva, Switzerland: WHO, 1996.

28 Alberman E, Blatchley N, Botting B, Schuman J, Dunn A. Medical causes on stillbirth certificates in England and Wales: distribution and results of hierarchical classifications tested by the Office for National Statistics. Br J Obstet Gynaecol 1997;104:1043-9.

29 Alberman E, Botting B, Blatchley N, Twidell A. A new hierarchical classification of cases of infant deaths in England and Wales. Arch Dis Child 1994;70:403-9.

30 Crowley P. Prophylactic corticosteroids for preterm birth. Cochrane Database Syst Rev 1996;CD000065 [DOI: 10.1002/14651858. CD000065]. 